\title{
La representación icónico-alegórica de lo sobrenatural en siete cuentos de aparecidos del Ecuador
}

\section{The iconic-allegoric representation on the supernatural in seven ghost stories from Ecuador}

\section{A representação icônico-alegórica do sobrenatural em sete contos de aparições do Equador}

\author{
Vicente Robalino \\ Pontificia Universidad Católica del Ecuador (PUCE) \\ E-mail: vrobalino@puce.edu.ec
}

\section{Resumen}

En este ensayo se hace un análisis e interpretación de siete cuentos de aparecidos del Ecuador, para ello se parte de la siguiente pregunta: ¿Cómo se construye la representación icónico-alegórica de lo sobrenatural en los cuentos seleccionados? Para responder a esta pregunta se analizan los espacios kinésicos y proxémicos de los relatos seleccionados. De estas dos categorías semióticas destaca la imagen icónica, como modeladora de los espacios de lo sobrenatural, unida a los espacios geográficos, donde trascurre la acción de estos relatos. De esta relación -espacio natural-espacio geográfico-emergen los efectos fantásticos. Sin embargo, en algunos de estos relatos, la presencia dominante de la alegoría-moralizante destruye la percepción de lo fantástico como en" Vico y el duende", "El enano (duende)" y en gran medida también en "Mariangula" En cambio, otros relatos, como, por ejemplo, "Almita en pena" se enriquece la imagen icónica de lo sobrenatural con la incorporación del rito y del símbolo. 
Palabras clave: semiótica, proxémica, kinésica, hermenéutica imagen icónica de lo sobrenatural, alegoría, símbolo, vacilación, pragmática

\section{Abstract}

This essay presents an analysis and interpretation of seven stories of ghosts -aparecidos- from Ecuador. In order to achieve that goal, the question 'How is the iconic-allegoric representation of supernatural built upon the selected stories?' is posed. To answer that question the kinetic and proxemic spaces of the stories are analyzed. From these two semiotic categories the one that stands out is the iconic image, as the shaping force of the spaces for supernatural, linked to the geographic spaces where the plot takes place. Fantastic effects emerge from this relation between natural space and geographic space. Nevertheless, in some of the stories the dominating presence of the moralizing allegory destroys the perception of the fantastic as in "Vico and the Goblin", "The Dwarf (Goblin)", and to a large extent in "Mariangula". On the other hand, other stories, such as "The tormented soul" the iconic image of supernatural is enriched with the incorporation of the rite and the symbol.

Key words: Semiotics, proxemics, kinetics, hermeneutics iconic image of supernatural, allegory, symbol, hesitation, pragmatics

\section{Resumo}

Neste ensaio se faz uma análise e interpretação de sete contos de aparecidos do Equador, partindo, para isso, da seguinte pergunta: Como se constrói a representação icônico-alegórica do sobrenatural nos contos selecionados? Para responder a esta pergunta analisam-se os espaços cinéticos e proxêmicos dos relatos selecionados. Destas duas categorias semióticas, destaca a imagem icônica, como modeladora dos espaços do sobrenatural, unida aos espaços geográficos, onde transcorre a ação destes relatos. 
Desta relação - espaço natural - espaço geográfico- emergem os efeitos fantásticos. Porém, em alguns destes relatos, a presença dominante da alegoria-moralizante destrói a percepção do fantástico como em "Vico y el duende", (Vico e o elfo) "El enano (duende)" (O anão (elfo)) em grande medida também em "Mariangula". Em contrapartida, outros relatos, como por exemplo, "Almita em pena” (Alminha penada) enriquece-se a imagem icônica do sobrenatural com a incorporação do rito e do símbolo.

Palavras-chave: semiótica, proxêmica, cinética, hermenêutica, imagem icônica do sobrenatural, alegoria, símbolo, hesitação, pragmática.

$* * *$

La palabra oral no solo se manifiesta como expresión hablada, que modeliza el sistema cultural al que pertenecen sus emisores, sino que está acompañada de todo un contexto kinésico y paralingüístico, como bien lo advierte Walter Ong: "Las palabras solo adquieren sus significados de su siempre presente ambiente real, que no consiste simplemente, como en un diccionario, en otras palabras, sino que también incluye gestos, modulaciones vocales, expresión facial y todo el marco humano y existencial dentro del cual se produce la palabra real y hablada" (Ong, 1987 , p. 52 ). A esta afirmación bien se podría añadir que la expresión oral requiere también de una representación del espacio contextual en el que se desarrolla el enunciado, es decir, de una proxémica en la cual el sistema de signos icónicos vaya también matizando el mensaje, como lo manifiesta el Grupo U, al ocuparse de la emisión de los signos icónicos: "La recepción de signos icónicos, por su parte, identifica un estímulo visual como procedente de un referente que le corresponde mediante transformaciones adecuadas;" (...) (Grupo U, 1993, p. 126 ). Precisamente, la imagen visual, que se junta al enunciado oral, al mismo tiempo que le da la impresión de lo real, va fijando en la memoria- 
la impronta- del espacio y de los seres y objetos que pueblan dicho espacio. Por esta razón, la pregunta que intenta contestar este trabajo es la siguiente: ¿Cómo se construye la representación icónico-alegórica en cinco cuentos pertenecientes a la tradición oral ecuatoriana? Dichos cuentos son estos: El duende en sus cinco variantes: "Los limoneros del duende, "El duende de Quinchuquí", "El duende del ciprés", "El enano (el duende), "Maríangulo" y "Almita en pena".

Lo sobrenatural, según Todorov, constituye una de las formas de lo fantástico, igual que lo extraño y lo maravilloso, se produce como una vacilación de quien solo conoce las leyes naturales: "Hay un fenómeno extraño que puede ser explicado de dos maneras, por tipos de causas naturales y sobrenaturales. La posibilidad de vacilar entre ambas crea entre ambas el efecto fantástico" (Todorov, 1981, p. 19). Aparte de este titubeo entre lo cotidiano y lo extraño, este mismo autor afirma que el efecto de lo fantástico implica "también una manera de leer "(Todorov, p. 24), es decir, una "integración del lector con el mundo de los personajes;" (...) (Todorov, p. 23). Todorov cree que lo sobrenatural no está confiado a cualquier lector, sino a una "función del lector implícito y de una función de narrador", que emergen de la propia textualidad. Desde esta perspectiva, Todorov se acerca a una de las líneas de la Teoría de la recepción, propuestas por W Iser.

Finalmente, este autor establece tres condiciones para que se pueda cumplir el efecto de lo fantástico: que los personajes sean asumidos por el lector como si fueran "personas reales" (el efecto de lo real), de tal manera que surja la duda entre "una explicación natural y una explicación sobrenatural de los acontecimientos evocados" (Todorov, p. 24). Que esta vacilación entre realidad y fantasía, el lector la pueda sentir, tanto en uno de los personajes como en el tema de la obra; y, que el lector mantenga su propia actitud frente al texto y rechace tanto una interpretación alegórica como una interpretación poética (Todorov, p. 24). Además, es importante, según Todorov, señalar lo precario del efecto de lo fantástico: (...) "Lo fantástico no dura más que el tiempo de una vacilación: vacilación común al lector y al personaje," (...) (Todorov, p. 31). 
De estas reflexiones de Todorov, en torno a los efectos de lo fantástico, debido a la presencia de la sobrenatural, es necesario destacar la relación no solo pragmática sino hermeneútica que este autor establece entre la imagen del narrador, la construcción y composición textuales y la imagen del lector, pues el efecto de lo real emerge de una experiencia figurativo-icónica compartida. Esta aprehensión de lo fantástico es comparable a uno de los ejemplos que pone Walter Ong, con respecto al reconocimiento que hace una comunidad oral (analfabeta) de distintas figuras al relacionarlas con sus propias vivencias cotidianas: "Los individuos analfabetos (orales) identificaban las figuras geométricas asignándoles los nombres de objetos, y nunca de manera abstracta como círculos, cuadrados, etcétera. Al círculo podía llamársele plato, cernedor, cubeta, reloj o luna; un cuadrado se designaba como espejo, puerta, casa o tabla para secar albaricoques" (Ong, p. 56).

A pesar de que Todorov no reconoce de manera explícita la dimensión cultural de los efectos de lo fantástico, dados por la presencia de lo sobrenatural, (lo sobrenatural es el mito) ni se refiere en su estudio a los textos provenientes de una tradición oral, quizá dicha dimensión pueda ser comparable también con los arquetipos y, en general, con la construcción de los mitos. En relación con lo primero, esto es, las imágenes arquetípicas, tal como lo expresa Yung: "Los arquetipos señalan vías determinadas a toda la actividad de la fantasía y producen de este modo asombrosos paralelos mitológicos, tanto en las creaciones de la fantasía onírica infantil como en los delirios de la esquizofrenia, así como también, aunque en menor medida, en los sueños de los normales y neuróticos.

No se trata entonces de representaciones heredadas sino de posibilidades de representación" (Jung, 2015, p. 94). Este mismo autor pone un ejemplo muy interesante para ilustrar la trascendencia de los símbolos y de los mitos para la cultura: "Si San Pablo hubiera estado convencido de que no era más que un tejedor ambulante de alfombras, no hubiera sido el mismo. Su vida real, su vida con sentido, se basaba en la certeza de que era el mensajero del Señor. (...) El mito que tomó posesión de él lo 
convirtió en algo más grande que un simple artesano.” (Jung, 2016, p. 68). En este mismo sentido podemos tomar los cuentos orales que hemos escogido. No importa si es que, por ejemplo, el duende se apareció o no a alguien, sino la trascendencia que tiene para la cultura el poder explicarse la presencia del demonio, creando una imagen de un hombre pequeñito con un sombrero inmenso que seduce a las muchachas y a las señoras que tienen el cabello largo. Lo mismo podemos decir del alma en pena, es esa presencia de lo sobrenatural lo que preocupa a una colectividad, no el hecho de que si existió o no. De allí que Todorov insista en que lo fantástico surge en el lector o en esa vacilación, en ese titubeo entre las leyes naturales y aquello que sale, en este caso por la imaginación colectiva, de ese ámbito.

En relación con la presencia de la alegoría en los relatos fantásticos, Todorov, en primer lugar, define a la alegoría, basándose, especialmente en la tradición retórica: [...]" la alegoría es una proposición de doble sentido, pero cuyo sentido propio (o literal) se ha borrado por completo" (Todorov, p. 46). En segundo lugar, afirma que la alegoría destruye, o al menos disminuye, los efectos de lo fantástico en la ficción: "Si lo que leemos destruye un elemento sobrenatural y, sin embargo, es necesario tomar la palabra no en sentido literal sino en otro sentido que no remite a nada sobrenatural, ya no hay cabida para lo fantástico" (Todorov, p. 47). Los cuentos seleccionados para este estudio oscilan entre la permanencia de lo sobrenatural y su destrucción por la orientación alegórico-moral del relato, igual que en las fábulas: Sin embargo, el relato que mantiene en toda su complejidad la imagen icónica de lo sobrenatural es "Almita en pena", como lo vamos a ver.

\section{El duende}

"El duende" es el relato de aparecidos que más versiones posee. Por esta razón se han escogido seis versiones que pertenecen a distintas provincias del Ecuador: una de Manabí, tres de Imbabura y otra de la 
Provincia de Tungurahua. Los compiladores de estas versiones, en su orden son: Rubén Darío Montero Flor, Verónica Reyes, Mónica Weiser, Claudia Torres y María Sol González, María Elena Chiriboga y Mario Conde.

\section{Los limones del Duende}

Este cuento está ambientado en el Cantón El Carmen, “en uno de los recintos olvidados de nuestra campiña, muy cerca de La Tablada de Limones, en una de las pocas casas que hay en aquel lugar" (Montero, 2013, p. 76). La trama desarrolla una de las facetas del Duende, la seducción. En efecto, una adolescente, Bella Inocencia Lema, es atraída por el lugar donde habita el Duende y se atreve a coger los limones del limonero, propiedad de este. La familia de la protagonista intenta, por todos los medios persuadirla y devolver los limones a su dueño. Sin embargo, el Duende muestra su furia y hace su aparición fantasmal en la casa de la adolescente: (...) "todos los parientes que estaban en la casa vieron cómo cuchillos, tijeras platos y las ollas de barro, caían al suelo aventadas por el duende" (Montero, p. 77) para, finalmente, el momento en que Bella Inocencia, junto con su familia, arroja todos los limones en la especie de cueva donde vive el Duende, este se olvida para siempre de ella. Es interesante anotar cómo en este relato, a diferencia del mito bíblico del paraíso, el seductor es él (el duende), y el árbol del pecado es el limonero y no las manzanas. Situación que se explica porque la región donde se ambienta el cuento-La Tablada de Limones- se caracteriza por la producción de este cítrico. Además, limón es un sustantivo masculino, a diferencia de manzana que es un nombre femenino.

Con respecto a la imagen icónica de lo sobrenatural, esta se construye con la presencia de espacios que van desde la particularización de la región geográfica-La Tablada de Limones-donde se desarrolla la acción de este relato, hasta la del barranco, donde - se supone- vive el Duende. Asimismo, la condición de deshabitado que posee el lugar, donde se va 
a dar el acto seductor, aunque fallido del Duende, contribuye a crear una atmósfera de miedo, especialmente para la familia de Bella Inocencia: "Su madre pega un grito de susto y le dice a la hija: "Muchacha de los mil demonios, no sabes que de aquel árbol nadie coge limones, porque ese árbol pertenece al mismo duende" (Montero, p. 76.). Sin embargo, esta muchacha rompe con la prohibición, a pesar de las advertencias de su madre: "Desde ese momento los padres de la joven se pusieron en guardia, porque ese mismo día la chica empezó a sentir pellizcones en todo su cuerpo y la casa se movía como hamaca"(Montero, p. 77). Otro elemento configurador de lo sobrenatural está formado por el limonero del duende que aparece de la noche a la mañana, según el comentario de la gente: "La gente comenta que de la noche a la mañana apareció el árbol, sin que nadie lo haya sembrado" (Montero, p. 76). De la misma manera, la muñeca de la protagonista adquiere también este mismo carácter: (...) "del cuarto de Bella Inocencia salía una de sus muñecas caminando y alzando sus manos, y apuntando a la muchacha y le hablaba de que le devuelva los limones" (Montero, p. 77).

La vacilación efímera que, según Todorov, experimenta el lector, propia del relato fantástico-como lo hemos visto-entre el mundo natural y el mundo sobrenatural, sí se produce en este cuento, pues el matiz alegórico no afecta a la estructura simbólica de lo sobrenatural. Además, no concluye, como las fábulas, con una moraleja.

Otro aspecto que complementa el carácter de oral e icónico de este relato es su configuración gestual y entonacional que le proporciona a este cuento plasticidad, como en estos ejemplos: "recogió los limones y los colocó en un canasto", "pega un grito de susto", "se persignó y aventó los limones para después salir en precipitada carrera" (Montero, p. 76 ), "echando rabietas", "se trepó al tumbado de la casa", "las fotos caían hechas pedazos", "Cogió las ropas y se las hizo pedazos". Cada una de estas fórmulas expresivas, que van dibujando una imagen sonora o una imagen visual revelan tanto al narrador oral como a su auditorio. 


\section{El duende de Quinchuquí}

Este cuento estáambientado en la hacienda Quinchuquí, ubicada en la provincia de Imbabura. Centra su tensión narrativa en los rumores y testimonios que rondan en este lugar sobre la existencia "real "del duende. Por ello, el relato diegético se limita a la constatación de esa presencia legendaria, del duende, por parte de un grupo de jóvenes, quienes en principio se muestras escépticos, hasta que, finalmente, son testigos de dicha presencia.

Las estrategias icónicas que utiliza este cuento se centran en los siguientes espacios: la hacienda de Quinchuquí, que representa el poder feudal, y donde, a las doce de la noche aparece el duende: "Comentaban que a las doce de la noche no se podía pasar por la hacienda de Quinchuquí, porque siempre aparecía el duende" (Hidalgo, 2000, p. 119). Además, los hacendados" tenían unos perros muy bravos". Por eso la gente del lugar decía: "Si no es el duende son los perros que no dejan pasar" (...) (Hidalgo, p. 119). Además otra de las imágenes icónicas centrales de este relato es la del retrato del duende, identificada por los jóvenes: "Dicen que lo vieron como que tenía, como que estaba cobijado con una sábana y con el sombrero muy grande, que no era alto, era una persona pequeña, pero que se pasó de una calle a la otra calle, haciendo ademán de como si tuviera alas debajo de la sábana y puesto el sombrero.”(Hidalgo, p. 120 ). A pesar de que los jóvenes ven al duende, no lo pueden identificar, pues está "cobijado con una sábana y lleva puesto un sombrero. De lo único que pueden dar fe es de su estatura: "que no era alto, era una persona pequeña". Además, por la rapidez con la que cruza la calle, los jóvenes suponen que el duende tiene alas: "haciendo ademán como si tuviera alas". Así el enigma sobre la apariencia física se mantiene. Sin embargo, la imagen icónico-sobrenatural que de él se tiene, no ha desaparecido de la memoria colectiva. Precisamente es esa memoria la que mantiene viva la imagen del duende y la trasmite a la nueva generación (a los jóvenes). En este relato, igual que en el anterior, se desarrolla la misma cualidad seductora que posee el duende, pero en este caso, no se refiere a la seducción amorosa, sino a la curiosidad que la figura enigmática del duende provoca en la colectividad. 


\section{El duende del ciprés}

En este relato, igual que en el primero, el duende va a poner en práctica sus cualidades de gran seductor que es, pues ya no es solo una imagen icónica sobrenatural sino una presencia encargada de perseguir a las señoras o señoritas guapas que tengan el cabello largo. Es decir que el duende: "Y así me conversaron, y que, a las señoritas y señoras, así guapas, que dizque tenían el pelo largo, que apenas pasaban a misa, madrugada, que dizque se aparecía el duende" (...) (Hidalgo, p. 121). Igual que en los cuentos anteriores, en este, el duende se aparece en un espacio concreto y a una hora determinada: "Que aquí hay una calle, una casa que le llaman la Tola. La llaman esta casa grandota, La Tola, y es en la calle Rocafuerte y allí hay un árbol grandote de ciprés, [...] (Hidalgo, p. 121). A diferencia del cuento anterior, en este, la imagen icónico-sobrenatural del duende se encuentra mucho más delimitada por la colectividad: "Y ha sido el duende un hombre chiquito y con sombrero grandote" (Hidalgo, p. 121). "Y así mismo, otra señora dizque ha dicho: -No, iqué va! [el duende] tenía los ojos grandotes y el pelo así mismo suelto," (...) “y ella del susto le queda viendo [al duende], dizque era un hombre chiquito, con ojos grandotes, y que se abría los brazos y no dejaba pasar." (Hidalgo, p. 122). Así en este cuento no queda la menor duda ni en los narradores testigos ni en el lector de cómo es físicamente, el duende. Sin embargo, su imagen sobrenatural se mantiene incógnita. Asimismo, el lugar donde hace su aparición el duende, igual que en los cuentos anteriores, se encuentra plenamente identificado: "Cuando dizque ella principia ya a bajar. Llega a todo el árbol y ipum! Se asoma de pronto el duende" (Hidalgo, p. 122).

\section{El enano (el duende)}

Este cuento sucede en Ayora, localidad de la provincia de Imbabura. En él un borracho se enfrenta con el duende, porque este se niega a ir a un molino viejo, que, según el narrador oral, está ubicado debajo de un puente, en Ayora. Esta negativa hace que el borracho intente golpearlo al 
Duende, sin conseguirlo: "El borracho se ha enojado y ha querido pelear con el enano. De ahí el borracho le ha tratado de pegar, pero no le ha dejado llegarse, no. Pero el enano sí le ha pegado fuerte" (Hidalgo, p. 124). Como consecuencia de este enfrentamiento, el borracho se enferma gravemente, tanto que ha tenido que recurrir a una limpia.

En este cuento no se desarrolla la imagen icónica de lo sobrenatural, puesto que el enano no aparece con poderes demoníacos ni seductores, como los que posee el duende en los cuentos anteriores. Sin embargo la aparición súbita del enano, y el espacio donde este vive, un molino abandonado, son inicios icónicos, para que el lector asocie al enano con el duende. Como afirma Todorov, según lo hemos comentado, la alegoría, destruye el instante de vacilación de lo sobrenatural. Esto es lo que sucede en este cuento, no hay desarrollo de lo sobrenatural, porque la literalidad del enunciado lleva a la moraleja: una persona no debe emborracharse ni caminar por la noche por lugares nada frecuentados.

\section{Vico y el duende}

Este cuento se desarrolla en Huambaló "una parroquia rural del cantón Pelileo, cerca de Baños" (Conde, p. 9), en la provincia de Tungurahua. El centro del relato es el pacto que Vico, un niño del lugar, hace con el duende, para jugar bolas por las noches. Este juego se convierte en un pretexto para que el duende se quede con el alma del niño, quien, finalmente, es salvado por su abuela por medio de una sesión de exorcismo.

Este relato posee varias dimensiones: una de carácter alegóricomoralista, otra de construcción de la imagen icónico-sobrenatural y una ritual. En la primera, el narrador-trascriptor califica al niño (Vico) de jugador y ambicioso y establece una especie de amenaza, en el sentido de que el duende persigue "a la gente, en especial a los chicos que se pasan en la calle jugando bolas hasta altas horas de la noche" (Conde, p. 
10). Así el juego se convierte en la metáfora, cuyo sentido literal es lo malo y pernicioso del juego, especialmente en las circunstancias en las que lo hace Vico, a altas horas de la noche, desafiando al duende y con la intención de ganar. En la segunda, igual que en los cuentos anteriores, en este la imagen del duende es la de un ser malévolo, que se identifica con el diablo, que vive en un lugar apartado del poblado-en la quebrada de Huambaló- y que se dedica a perseguir a la gente que deambula por las noches, especialmente a los niños. Sin embargo, la descripción física que se hace del duende en este cuento es un tanto diferente a la de los otros relatos, pues este lleva "un sombrero negro enorme como los que usan los mariachis", "su rostro era negro y velludo, usaba poncho rojo, tenía los pies chiquitos y las manos inmensas y deformes" (Conde, p. 10).

Sorprende de esta descripción la comparación del sombrero, la deformidad de su cuerpo y el poncho rojo con el que se cubre. Con respecto a la primera, esto es, la comparación del sombrero del duende con el de los mariachis, hace pensar que la versión de este cuento es contemporánea y está relacionada con las fiestas que se realizan tanto en las ciudades como en las zonas rurales, donde la presencia de los mariachis es muy común. En relación con la segunda- el aspecto deforme del duendese puede apreciar que estas facciones repulsivas que el duende posee están en relación con su no menos despreciable personalidad, pues es uno de los representantes del demonio. Finalmente, el poncho rojo que usa el duende tiene que ver con un nexo de identidad con la zona donde se sitúa el cuento, Huambaló, pues el poncho es una prenda de vestir especialmente indígena y el color rojo, es una cualidad vinculada con el demonio. Los ritos que se celebran en este cuento-en realidad son dos-, el primero es aquel que hace Vico cuando va a la iglesia y sumerge en agua bendita las bolas de cristal, para poder ganarle el juego al duende: "Al oscurecer, se dirigió a la iglesia. Entró allí en forma disimulada, mojó en la pila de agua bendita las bolas que traía en el bolsillo y se las guardó" (Conde, p. 12). El segundo, se refiere al que realiza la abuela de Vico para evitar que el duende se lleve el alma del niño: "Otra vez era la abuela. Ella traía un fuerte y una botella de aguardiente en una mano 
y un paquete de cigarrillos en la otra. Puso la botella y los cigarrillos en el suelo, a un lado del maligno, y gritó en forma amenazante: ¡Duende, duende! ¡Prefieres fuete o aguardiante? En el acto el demonio tomó las cosas del suelo y desapareció" (Conde, pp. 14-15). De esta manera el bien triunfa sobre el mal. Aunque la imagen icónico-sobrenatural del duende vive en la comunidad, en este cuento, la alegoría-moralista, a la que parecería reducirse esta historia, amenaza constantemente con destruir la vacilación lectora entre lo real y lo icónico, es decir, el instante del efecto fantástico.

\section{Mariangula y Almita en pena}

Estos dos cuentos se relacionan en cuanto construyen la imagen icónica de lo sobrenatural en el espacio del cementerio. Se diferencian porque el primero-Mariangula- desarrolla el tema del horror y lo profano; mientras que el segundo-Almita en pena-se concentra en lo sagrado, la pureza, el cielo. Igual que en el cuento anterior-Vico y el duende- en Almita en pena, su protagonista es un niño. En tanto que en el cuento de Mariangula, una adolescente de catorce años. Mariangula narra la historia de la muchacha, con este mismo nombre, que para evitar el castigo de su madre, quien le había pedido comprar tripas y puzún, decide profanar una tumba y extraer la vísceras de una difunta: "En una ocasión, antes de salir a las ventas en un famoso parque en Ibarra por sus puestos de comida al atardecer, la madre encargó a Mariangula que fuera al camal a comprar las tripas y el puzún para el próximo día" (Conde, p. 58). Pues la desobediencia de Mariangulo , el temor a ser castigada por su madre y los consejos de un carnicero ("Si quieres librarte de una buena paliza, será mejor que caves una tumba y robes las tripas de un muerto" (Conde, p. 59) hacen que, efectivamente, esta muchacha acuda al atardecer al cementerio y hurte las tripas y el puzún de una persona muerta.El alma de la difunta toma venganza y hace lo mismo que había hecho la protagonsta, es decir, arranca las vísceras de Mariangula en medio de una escena de terror. Escena que empieza con el estribillo recriminatorio del alma de 
la difunta: "Marianguuuula, devuélveme las tripas y el puzún que te robaste de mi santa sepultura" (Conde, p. 62). Este cuento tiene por lo menos dos lecturas, gracias a la presencia de dos imágenes icónicas de lo sobrenatural, formadas por la profanación de la tumba y por la venganza del alma de la difunta profanada, respectivamente. La primera lectura sería la meramente alegórico-moralista: el castigo por la desobediencia a los padres. La segunda, recrea, como lo hemos anotado, toda una compleja configuración de la imagen de lo sobrenatural, cuyos efectos son el terror que comparten tanto el lector como la protagonista de este cuento.

El cuento "Almita en pena" por una parte desarrolla el tema de la ascensión al cielo del alma de un niño, por otra, robustece esta imagen icónica de lo sobrenatural mediante la intercalación de los rituales que giran en torno a la muerte como el vestir de blanco al niño muerto, junto con los mitos que emergen de este mismo asunto: (...) "los familiares nunca visten a un difunto porque este podría llevárselos; así es que la curandera del pueblo fue quien arregló al niño para el entierro" (Conde, p. 18). Igualmente es significativo el rito del velorio: "Mientras el padre bailaba con la madrina, el hermano mayor, un chico de unos nueve años, tomó unos caramelos de una bandeja y fue a ponerlos en las manos del difunto" (Conde, p. 18). No menos importante para el desarrollo de la imagen de lo sobrenatural es, en este cuento, la visión que los personajes tienen del alma, a través de la mirada de un perro: "Entonces explicó que los perros pueden ver seres del más allá, y que al untarse las lagañas del perro sus ojos serían como los del animal y podrían ver el almita en pena" (Conde, p. 19). De la misma manera la descripción del alma por parte de un anciano adquiere la dimensión de lo extraño, otra categoría de lo fantástico, de aquello inaprensible, pero al mismo tiempo existente: "Sobre la mesa, donde estaba el ataúd, vieron una pequeña forma, como una sombra blanca, que flotaba por el lugar. El anciano recordó al chico que el alma no podía verlos" (Conde, p. 19). Este es un clarísimo ejemplo de la vacilación del lector, señalada por Todorov; vacilación que oscila entre la realidad y el imaginario colectivo. 


\section{Conclusión}

Este ensayo nos ha permitido ver la complejidad que poseen los cuentos seleccionados, pues están compuestos por un entretejido de discursos provenientes de la oralidad como la enunciación múltiple, la contextualización gestual, entonacional e icónica y la visión de lo sobrenatural que posee una colectividad con respecto al mundo real y a su trasformación fantástica, dentro del ámbito de lo sobrenatural. Precisamente esta categoría de lo sobrenatural no es un elemento individual ni solo encargado de producir miedo y hasta terror; sino que está unida a toda una reflexión colectiva, moral e imaginaria, en torno al bien y al mal, a dios y al demonio y que no surge al azar sino como una experiencia de vida de lo cotidiano y muy fuertemente vinculada a los espacios geográficos, generalmente rurales, donde la comunidad afirma ha sucedido tal o cual hecho.

La imagen icónica de la que hemos hablado, a lo largo de este trabajo, ha permitido mostrar cómo la colectividad construye lo sobrenatural, primero como una presencia arquetípica que subyace en esa sociedad y luego como una manifestación histórica, geográfica y social de dicha sociedad. Para el develamiento del efecto de lo fantástico nos ha sido muy útil el concepto de vacilación, empleado por Todorov y el de arquetipo de Jung, pues bajo estas consideraciones teóricas han emergido ritos, símbolos y mitos sometidos, para tomar un concepto de Peirce, en un proceso constante y dinámico de semiosis; en este caso de semiosis de lo sobrenatural. 


\section{Referenciasbibliográficas}

Conde M. (comp.) (2005). Cuentos ecuatorianos de aparecidos. Quito: Norma.

Grupo U (1993). Tratado del signo visual. Para una retórica de la imagen. Madrid: Cátedra.

Hidalgo.L. (comp.) (2000). Mariangula y otros aparecidos. Quito: Eskeletra y Alianza Francesa.

Jung C. (2016). Escritos sobre espiritualidad y trascendencia. Madrid: Trotta.

(2009). Arquetipos e inconsciente colectivo. Buenos Aires: Paidós.

Montero. R. (comp.) (2013). Cien leyendas y cuentos de la campaña manabita. Portoviejo: Gobierno autónomo y descentralizado del cantón Portoviejo.

Ong. W. (1987) Oralidad y escritura. Tecnologías de la palabra. México D.F.: F.C.E.

Todorov T. (2006) Introducción a la literatura fantástica. Buenos Aires: Paidós. 